\title{
Increasing Human Security to Disaster Risk Targeting Vulnerable Communities in the North of Haiti
}

\author{
Article by Pierre Edwidge Moise \\ MBA Texila American University \\ Email:edwidge3000@yahoo.fr
}

\begin{abstract}
Human Security was never a concept used in Haiti in the past. As disaster in this country remain a critical factor, the concept become more important than ever. Human Security can respond to the complexity of emerging security threats in an integrated manner. Human security protect the vital core of all human lives. It is important to use processes that build on people's strengths and aspirations. It means creating, social, environmental, economic and cultural systems that together give people the building blocks of survival, livelihood and dignity. This project work respond to those needs. It is all about empowerment and protection. With this concept, institutions are reinforce with a focus on capacity development of keys partners locally and regionally. The North department was a key focus to build that capacity targeting vulnerable communities. By addressing the full range of insecurities faced by the targeted communities in the North, the project promotes responses that are community-driven, preventive and sustainable in the long run.
\end{abstract}

\section{Introduction}

To date, much of the work on human security has focused on threats emerging from war and conflict. Disasters have largely been overlooked, despite being now identified by the international community as a major threat to human security. They cause many of the same problems as conflict - such as large scale destruction and extensive displacement and contribute to Human Rights violations and heightened vulnerability, especially of the most marginalized groups and individuals.

Haiti is one of the most vulnerable countries to disasters in the world and the North Department is one of the most disaster prone areas in Haiti. In such a highly disaster prone country, preparedness and risk reduction are critical components of human security.

From 1909 to 2013, Haiti has faced over 100 disasters primarily caused by hydro-meteorological hazards of which 30 cyclones, 47 extensive floods, 7 droughts and 2 earthquakes. Cyclones, landslides and droughts are the phenomena that most impact the agricultural sector, which represents the most important source of income for Haitian households. Since 1963, approximately 240,000 people have been killed and over 9,000,000 people have been affected by disasters in the country.

Haiti has in recent years experienced rampant urbanization, at a rate of approximately $3.9 \%$ per year since 2001. Haitian urban development has been characterized by anarchic occupation of high-risk areas and the lack of application of building codes, aggravating environmental degradation and human insecurity. The January 12, 2010 fatal earthquake was a sharp reminder of the country's extreme vulnerability to seismic risk.

The effects of disasters and lack of appropriate protection mechanisms have a significant impact on pre-existing vulnerabilities, which are exacerbated if the needs of the most affected individuals cannot be met.

There is also a clear link between disasters and food insecurity. In 2012, the prevalence of food insecurity was up to $43 \%$ in the rural areas that had been affected by Cyclone Sandy; the next year the rate had diminished to $27 \%$. Food insecurity is more relevant in rural areas $(12,9 \%)$ than in urban areas $(8,3 \%)$.

Among the 10 departments of Haiti, the North Department is one of the most disaster prone areas in 
DOI: $10.21522 /$ TIJAR.2014.04.02.Art003

ISSN: $2520-3088$

Haiti. Due to its proximity to the "Septentrionale" fault, earthquake risk is highly elevated. More than $73 \%$ of the municipalities are at risk of flooding, $36 \%$ at risk of landslides, and $21 \%$ at risk of tsunami.

The high population density in urban and peri-urban areas is an exacerbating factor of the environmental insecurity, especially of the poorest communities. The absence of a risk-sensitive urbanization plan is an environmental factor that must be addressed. Moreover, the unplanned urbanization has led to the creation of urban areas that have no access to basic infrastructure and public services, increasing the health insecurity of individuals.

Epidemics in general, specifically cholera and malaria, see increasing peaks during the rainy seasons especially as a result of the absence of infrastructures, lack of household latrines, and weak awareness around the behavioral preventive measures. The most vulnerable municipalities are Bas Limbe, Acul du Nord, Limonade and Plaine du Nord. Throughout the department, $31 \%$ of the population has no access to potable water and adequate sanitation infrastructures.

\section{Rationale}

Since the creation in 2001 of the National System for Disaster Risk Management (SNGRD), Haiti has made significant progress in increasing its capacity to prepare for and manage the impact of disasters especially on the environmental and economic security. However, millions of Haitians are still face high degrees of insecurity due to disaster risk - significant efforts are still required to strengthen capacities to prepare for and recover from disasters. In such a highly disaster prone country, preparedness and risk reduction need to be a priority in order to increase human security.

An assessment based on past experiences and consultations with key stakeholders including the United Nations methodology of Gender Impact Assessment have demonstrated the need to strengthen overall capacities in relation to risk monitoring and assessment, preparedness and response, risk reduction and mitigation, especially at community levels in order to address specific insecurities. Such efforts must be conducted whilst empowering the most vulnerable communities and ensuring appropriate institutional capacities to protect. An adequate response to these needs will build the resilience of individuals that are most insecure to disaster hazards, thereby ensuring that communities will reduce their exposition to disaster risks and recover from sudden shocks.

The institutional coordination mechanisms, that bring together all disaster risk reduction actors (line ministries, UN agencies, NGOs, private sector and civil society), have made significant progress in recent years. However, these coordination mechanisms often lack the technical and financial capacities to appropriately address the needs of the most vulnerable individuals in a holistic manner. This impedes the implementation of adequate strategies to improve the identification and monitoring of risks, define preparedness and response strategies to disasters in a participatory and representative way, while establishing urban planning and risk mitigation initiatives that reflect the specificities of the insecurities of the population.

Moreover, the communities are often not consulted when identifying risks or developing and implementing disaster risk reduction strategies. A genuine prospect of sustainable development and human security can only be achieved if communities are empowered to take on an active role in managing risks and government institutions commit to offering protection for the most vulnerable.

This project was planned to secure community ownership by the most vulnerable communities with a particular focus on women, children and youth - in the North department, thereby addressing the specific insecurities they hold. As such, the project bring together UN agencies, local authorities and local communities through the partnership with UNESCO and Oxfam who have extensive expertise in the North Department and have been working with local communities in this domain.

The Government of Haiti and the United Nations have been engaged since April 2013 in the Political Champions Group for Disaster Resilience initiative. It defined a new approach in addressing disaster risk, by building the resilience of vulnerable populations to disasters through a coordinated and cross-sector integrated program that addresses major insecurities (social, environmental and economic) 
that exacerbate the effects of disasters. The initiative is focused on three pilot departments exposed to natural hazards, among which the North department.

In February 2014, the Political Champions Group for Disaster Resilience in Haiti (including government line ministries, UN agencies, NGOs and civil society) conducted technical missions in the pilot departments in view of developing specific investment programs to strengthen the resilience of communities to disasters. The project addresses a number of priorities identified in the investment program for the North department, thereby contributing to the advancement of the disaster resilience agenda in Haiti, with an emphasis on improving human security in a holistic manner.

Moreover, all partners engaged in this project have a thorough understanding and experience in matters related to disaster risk reduction, disaster risk management, and overall reinforcement of human security in relation to disasters in Haiti and in the North Department.

This initiatives integrate elements of on-going projects - and therefore co-funding- such as the project for Seismic Risk Reduction in the Great North of Haiti (UNDP 2011-2015), Supporting Disaster Resilience in the Highly Vulnerable Northern Department of Haiti (UNDP 2015 -2017), Reinforcement of the decentralized National System of Disaster Risk Reduction (UNDP /French Red Cross 2014-2017), and Project DIPECHO Tsunamis in the island of Hispaniola (UNESCO 2012-2014).

The profound expertise of OXFAM and UNESCO with regards to reinforcing the leadership role of women, children and youth allowed this project to address the specific insecurities of the most vulnerable groups, which are often not taken into account.

Human security is meant to entail "freedom from fear" and "freedom from want," a situation in which people can live their lives with dignity. To date, much of the work on human security has focused on threats emerging from war and conflict. Disasters have largely been overlooked, despite being now identified by the international community as a major threat to human security. This reflects the evidence that disasters cause many of the same problems as conflict such as destruction on a large scale, extensive displacement, violation of Human Rights, and heightened vulnerability in particular those who belong to marginalized groups.

Disasters are almost always the result of both natural phenomena and human action. Nowadays, due to climate change and its impact on the environment, disasters are occurring with increasing frequency and intensity. When disasters - such as a drought, flood, earthquake and tsunami strike people's livelihoods and ability to continue with day-to-day life are affected, whether directly or indirectly. Disasters exacerbate the underlying social, economic, political and environment insecurities, stalling economic and social progress with results on the human security of those most vulnerable and leading to a reduction in the protection and empowerment of this group.

Due to gender dynamics in the communities, women are the most affected by disasters because they affect their financial autonomy, increase their work load, expose them to violence and sexual abuse. There is increasing evidence that pre-existing social, economic, political and environmental conditions determine the impact of disasters. Their roles are rarely taken into account and valorized during risk analysis and preparedness.

In light of the major vulnerability of the communities of the North department of Haiti to disasters, the project intended to address in a holistic matter all aspects that can contribute in strengthening the security of the most exposed individuals. The North department is the most appropriate to promote the Human Security approach, due to the presence of ongoing programs implemented by the UNDP, UNESCO and OXFAM and the limited empowerment and participation of the most vulnerable communities with regards to disaster risk management measures.

In line with the Human Security methodology and the "Protection and Empowerment" framework, the envisaged initiatives focus on promoting an approach in which the individuals are not only beneficiaries, but real actors of change. Moreover, the project contributed to the reinforcement of the institutional structures that have the responsibility of protecting their citizens and allowing them to appropriately carry out their daily lives without being subjected to unexpected shocks that chronically 
DOI: $10.21522 /$ TIJAR.2014.04.02.Art003

ISSN: $2520-3088$

endanger the integrity of their lives and livelihoods.

The nature of the constituted partnership for the development of the project is representative of the various aspects that needed to be taken into account in order to ensure human security in relation to disasters. After having carried an in-depth analysis of the human insecurities related to disasters, including the United Nations methodology of Gender Impact Assessment, all partners have underlined the necessity to include actors at all levels and of different expertise in order to ensure that all actions are complementary and contribute to the achievement of the intended result.

The Human Security approach is an exemplary method to address chronic vulnerabilities to disasters and shed light on those specific insecurities that entail a chronic weakness of the lives and development of the most fragile communities. Moreover, the funding of the project gave the opportunity to various UN agencies to approach the communities in a more direct way and not focus the entirety of their efforts on the institutional mechanisms which often do not reflect the difficulties encountered by the most disadvantaged populations in particular women, children and youth.

For this reason, the project contains elements, such as the development of a study on the benefits of the Human Security approach in humanitarian and development programs in Haiti to strengthen disaster resilience. This approach was promoted within the UN System and the international community in general while advocating for the adoption of this method among governmental counterparts.

\section{Objectives and outputs}

Objective 1. The human security of vulnerable communities is improved through an increased participation in the construction of knowledge of disaster-related insecurities and their integration in disaster risk management strategies, at the local, municipal and departmental level

It is noteworthy that communities at risk are very often aware of the risks they face. Less frequent hazards as earthquakes and tsunamis may be less known and need to be integrated in a multi-hazard approach. The main objective of enhancing risk knowledge is to understand social representations that are being shaped and influence decision-making and behavior change. It is important to integrate communities in the study and analysis of natural hazards and vulnerability.

Understanding the interaction of hazards, exposure and vulnerability is crucial to effective disaster prevention and resilience. Multi-risk assessments are therefore fundamental to help provide access to analysis and information on risk and vulnerability factors associated with disasters

The initiatives was carried out through the direct participation of the chronically affected communities that provided detailed and disaggregated data in order to allow the developed assessments to appropriately reflect the specific insecurities that prevail in the target area.

Output 1.1. Knowledge on disaster risks is increased among local, municipal and departmental stakeholders, including the specific impact according to gender.

- Developed and disseminated an integrated multi-risk assessment (earthquake, tsunami, marine submersion, flood, land slide, rock falling, debris flow, and storm) for the North department, combining technical and participatory approaches.

- Conducted an assessment of the human, socio-economic and environmental issues of the target area, with a focus on specific vulnerabilities related to gender;

- Conducted evaluation of three main critical infrastructures of the target area;

- Developed Risk Prevention Plans for targeted municipalities on the basis of the Departmental Risk Assessment and the identified human, socio-economic and environmental vulnerabilities of the target area;

- Strengthened the capacities of local authorities to consider the findings and adopt the recommendations of the multi-risk assessment, through a combined technical and participatory approach.

- Disseminated, communicated and raised awareness on the findings and recommendations of the integrated departmental multi-risk assessment Risk Prevention Plans, at the local, municipal and 
departmental level with a particular emphasis on empowering people with specific vulnerabilities (including women, girls and those with disabilities).

Objective 2. The insecurities towards disasters of the most vulnerable communities are addressed holistically by the main disaster risk reduction stakeholders at all levels.

The departmental and local coordination mechanisms, which focus on disaster preparation and response, do not always have the necessary means to ensure an active coordination with other stakeholders. This causes the initiatives to not take into consideration other long-term aspects, such as a disaster risk reduction, risk mitigation and disaster resilience. Through the project, the formal coordination mechanisms improved the outreach and inclusion of non-governmental actors (NGOs, community based organizations and the private sector) in view of integrating in a holistic way the insecurities of the most vulnerable populations in the disaster risk reduction and management strategies. The initiatives, thanks to its people-centered approach and case studies, lessons learned and testimonies provided new insights on the value of the human security approach in relation to disaster resilience. Through the development of a foreseen study, an advocacy strategy to integrate the human security concept in disaster risk reduction and management approaches implemented towards all relevant stakeholders, at all levels.

Output 2.1. Specific insecurities of vulnerable communities are addressed through the strengthening of cross-sector coordination and operation of disaster risk management stakeholders, at the community, municipal and departmental level.

- Strengthened the capacities of cross-sector disaster risk management coordination bodies in addressing human securities, at the community, municipal and departmental level;

- Strengthened operational capacities of the local committee of the Haitian Directorate of Civil

Protection with a focus on protection of the most vulnerable

Output 2.2. A human security approach, with an emphasis on protecting the most vulnerable, is adopted in disaster risk management programs of key civil society, government, and international actors

- Conducted a study on the benefits of approaches that promote human security in disaster resilience programs in Haiti, on the basis of this innovative project and in view of broadening its impact;

- Promoted and advocated for the holistic integration of specific insecurities of communities that are vulnerable to disasters in disaster risk management interventions (e.g. in the education system), including the protection role of government institutions;

- Strengthened the capacities of the Ministry of Status and Rights of Women, for a greater involvement in disaster risk reduction initiatives with a human security approach.

Objective 3. Insecurities are addressed by the targeted communities through their empowerment and participation in decision-making processes and development of disaster risk reduction strategies

Through this project the empowerment targeted vulnerable people was reinforce and manage contextspecific and culturally-adapted multi-hazard disaster risk reduction strategies, including Community Action Plans and Community-based Early Warning Systems (CEWS). The implementation of such strategies was a complex endeavor, demanding multisectoral approaches and needed to be anchored in a protective structure implemented by the State. In this sense, the Community Action Plans and especially the CEWS should be linked and provide feedback to the central and departmental level.

Output 3.1. Relevant technical capacities are acquired by community-based organizations to further their leadership in designing and implementing disaster risk management activities

- Conducted trainings for the development of Community Action Plans based on the Risk Prevention.

- Provided support to communities for the implementation of Community Action Plans;

- Conducted an inventory on good practices on disaster preparedness and response at the community level, and render them accessible to a broader audience;

- Provided training and support for the development and implementation of community early warning systems linked to departmental-level systems, through a participatory approach and a particular focus on women and youth. 
DOI: $10.21522 /$ TIJAR.2014.04.02.Art003

ISSN: $2520-3088$

Output 3.2. The organizational capacities of civil society organizations and government structures at the local level are strengthened to further the empowerment of communities in disaster risk management.

- Strengthened the capacities of volunteers and other community-level structures, with a focus on protection of the most vulnerable;

- Promoted partnerships and integrate local women's organizations and network with existing disaster risk management mechanisms.

Output 3.3. The extended school community has a reinforced capacity to address its insecurities and implement tailored disaster prevention and management protocols.

- Conducted trainings and support to teachers and schools inspectors for the development and implementation of tailored protocols for disaster risk prevention and management;

- Conducted trainings and awareness raising initiatives towards teachers, school inspectors, pupils and parents in disaster preparedness and response, through the participation of all stakeholders.

Output 3.4. Women and youth are empowered to address their insecurities through a greater participation in the design and implementation of disaster risk management strategies.

- Conducted training and awareness raising activities targeting women, youth, and men to increase the participation of women and youth in the design and implementation of disaster risk reduction activities.

- Support gender mainstreaming in the development and implementation of community early warning systems

Objective 4. The human security of targeted communities is increased through the reduction of their exposure to natural hazards.

Output 4.1. Communities are empowered to collectively design and implement measures to mitigate risks posed by natural hazards.

- Provided technical expertise and resources to community-based organizations for the design and implementation of small-scale disaster risk mitigation projects.

\section{Target area}

The project targeted the communities of the vulnerable urban corridor from Cap Haitian to Limonade in the North department of Haiti. The choice of the North department was in line with the strategy defined by the Government of Haiti as part of their leadership of the Political Champions Group for Disaster Resilience initiative.

The exact number of direct beneficiaries is difficult to express at this stage because the communities that was directly benefit from the project was determined through the development of the departmental risk assessment and the assessment of the human, socio-economic and environmental issues with a focus on specific vulnerabilities related to gender both foreseen in the project.

However, it is safe to say that the entirety of the population of the North department was indirectly benefit from the implementation of this initiatives, especially from those related to the reinforcement of the formal coordination structures, the multi-risk assessment, and public education and awareness raising initiatives:

- Cap Haitian - 155,000 people

- Petite Anse- 89,000 people

- Limonade - 14,000 people

- Coast of de Limonade - 1,000 people

- Commune of Quartier Morin - 3,500 people (urban) + 21,000 (rural sections)

In order to address the assessed gaps in the most appropriate and sustainable way, the global goal of the project was to increase the human security of targeted communities that are vulnerable to disasters in the Cap Haitian- Limonade corridor, with a particular attention to women, children and youth. 


\section{Methodology}

The project was developed following the evaluation tools provided by the Human Security Unit, in particular "Designing a human security program/project". The implementing partners (UNDP, UNESCO, and OXFAM) participated in specific exercises to identify the human insecurities in the North Department and decide what changes needed to be obtained through the project.

In particular, the elements included in the project were developed in a two phase process:

1. Secondary data: analysis of lessons learned from current projects.

2. Primary data: identification of disaster risk reduction needs through specific exercises and in-field consultations, meetings with the representatives of the Departmental Committee of Civil Protection, Gender Ministry, other stakeholders and community-based organizations in the target areas. A workshop was organized mainly with civil society organizations in order to identify the current needs on disaster risk reduction from a human security perspective.

These consultations allowed the proposal team to consult various levels and triangulate data on insecurities faced by the target population. This process led to an adequate identification of the needs to be addressed and of the most appropriate actions to undertake.

The project has obtained official validation of the Haitian Directorate of Civil Protection, which is the main governmental counter-part for the implementation of the initiatives.

\section{Implementation}

The UN agencies involved in the project have a tremendous amount of experience to support changes in matters related to Disaster Risk Reduction Management in the North Department of Haiti. Moreover, each agency is an active participant of the Political Champions Initiative and therefore thoroughly involved in reducing insecurity of the most vulnerable populations through a holistic approach that addresses all insecurities that threaten the integrity of the most exposed individuals.

To achieve the goals, the existing partnerships of the implementing agencies was reinforced with all relevant stakeholders, in particular the decentralized government instances such as the Directorate of Civil Protection and the Departmental Committee of Disaster Risk Reduction and the community-based organizations in order to ensure the "protection-empowerment" approach throughout all phases of implementation.

To guarantee an appropriate outreach and active engagement of the local communities, the UN Agencies selected an experienced and geographically well-established partner to translate all actions at local and community levels and guarantee the envisaged impact on the human security of the targeted populations.

To do so, the UN agencies decided to partner with OXFAM, an International NGO that has been involved for more than a decade in community disaster risk reduction in the North Department. OXFAM works closely at local and community levels with Community Based Organizations, local NGOs and local authorities to empower them, and most importantly, to add in their agenda the gender equity topic. OXFAM worked to support those actors, men and women, to be able to take part in the decision processes and influence the leaders, authorities to make strong decisions in order to change their lives.

\section{Sustainability and conclusions}

The "protection-empowerment" framework that was implemented through the project guaranteed the sustainability of the achieved results through time. The implementation of such framework allowed to strengthen the capacities of the targeted communities to understand and act upon their vulnerabilities. The communities, which are often mere beneficiaries, was the main actors of change.

Moreover, in order to ensure an environment which allows the communities to develop and grow as active citizens, the initiatives also targeted the formal and institutional protection mechanisms that guaranteed an adequate consideration and assistance of the most vulnerable, before, during and after a crisis. The coordination structures that was reinforced through this project enable the continuous revision, 
DOI: $10.21522 /$ TIJAR.2014.04.02.Art003

ISSN: $2520-3088$

test and improvement of the methodologies and processes developed.

The particular focus given to women, youth and children strengthened the acknowledgement of the central role of these specific groups in the development and implementation of disaster risk reduction strategies, at all levels. This is an imperative factor, given that it has been proved that the active participation of women allows continuity of implementation of activities and behavioral change as they are the main channels of knowledge transfer. The integration of the Women Affair Ministry at all stages of the project and activities reinforced an institutional integration of the gender equity aspect in disaster risk reduction. In the future, much more analytic projects needs to be implemented by the Government of Haiti while involving the media to bring awareness to the population that can bring resilience in disaster situation when they occur.

\section{References}

[1].EM DAT (1963-2013), retrieved from http://www.emdat.be/"Human Security and Natural Disasters"-United Nations University Institute for Sustainability and Peace retrieved from http://isp.unu.edu/research/human-security. [2].Index Mundi - estimation (2010-2015), retrieved from http://www.indexmundi.com/commodities/ Mission technique Nord - (2013) Political Champions of resilience, UNDP Haiti report 2014 retrieved from http://www.undp.org/.

[3].Population census- (2009). Haitian Institute of Statistics and Information (IHSI), retrieved from http://www.ihsi.ht/ "The Human Security Implications of Natural Disasters: the recent cases Pakistan and Haiti" Carlos António Carvalho Observatory for Human Security, ISCSP-UTL (January 2011).

[4].UNDP Capacity Analysis of preparedness and response, Bureau for Crisis Prevention and Recovery (2013), retrieved from http://www.undp.org/. 